\title{
Satellite missions face shut-down as NASA tackles cash squeeze
}

Washington. A panel of space scientists is to meet later this month to help the US National Aeronautics and Space Administration (NASA) to decide which astrophysics satellites should have their lifetimes extended and which may have to be shut down for lack of money.

Although NASA managers conduct a similar exercise every two years, this year's 'senior review' by scientists from outside the agency promises to be the toughest yet. The agency's budget for mission operations continues to decline, while the number of spacecraft returning data beyond their planned lifetimes is growing.

The panel will judge the scientific merit of extending three US missions scheduled to end in 1997 and 1998: the Extreme Ultraviolet Explorer (EUVE), the Compton Gamma Ray Observatory (GRO) and the Rossi X-Ray Timing Explorer (XTE).

Also to be decided is continued US participation in several international missions: Japan's ASCA X-ray satellite, the German-led ROSAT X-ray mission, Italy's Beppo-SAX, Japan's VLBI Space Observatory Programme (VSOP), and grant support for US users of Europe's Infrared Space Observatory (ISO).

These missions will cost NASA a total of $\$ 38$ million next year. This should present no difficulty, says Guenter Riegler of NASA's science office. The problem comes in 2000, when the budget for these projects will go down to $\$ 6$ million. "Clearly something has to give," says Riegler, adding that the agency may need to terminate some missions earlier than others to save money for later in the decade.

After hearing from the review panel, NASA will decide next month which spacecraft, if any, should be shut down, and when. The agency plans to conduct similar exercises for its space physics and planetary programmes within the next two years.

No one inside or outside NASA relishes throwing away a working satellite. But the agency did just that by deciding, on the advice of previous review panels, to abandon the ailing but still productive International Ultraviolet Explorer (IUE), which will shut down in September after a brief period of European ownership.

The IUE decision was "a big psychological barrier", says Riegler. He says that such painful decisions may become increasingly common as the space agency's operational budget dwindles.

While NASA may budget only for a twoor three-year mission, spacecraft routinely last longer, returning useful data for five or more years. The problem is exacerbated by NASA's current philosophy of launching more small satellites, more often.

"The thinking now seems to be "better, cheaper, faster, then throw it away'," says one scientist, who argues that investigators often need a year or two to work with new spacecraft instruments before they get the most out of them.

Many scientists are also concerned that the squeeze on budgets means that more money is being spent on keeping hardware

\section{IMAGE UNAVAILABLE FOR COPYRIGHT REASONS}

On the bright side: scientific merit is likely to help the Gamma Ray Observatory survive.

flying than on supporting science. Project scientists already report that funding for data analysis has shrunk disproportionately, with fewer researchers getting ever smaller grants to analyse spacecraft results.

If NASA wants to continue launching missions with new sensors, it cannot afford to keep older spacecraft flying indefinitely. Most space scientists acknowledge that this is a genuine dilemma in an era of declining budgets. "NASA really does want to do the right thing," says Fred Seward, a member of the ROSAT team at the Harvard-Smithsonian Astrophysics Observatory. He laments: "I feel like we're at war, and we're trying to defend ten cities, and we're told we can only defend five - which ones do we want?"

Continued US participation in ROSAT and ASCA may be hard to justify this year, particularly with a small armada of X-ray satellites already flying, and the US Advanced X-Ray Astrophysics Facility and European XMM missions scheduled for launch in 1998 and 1999 respectively.

Extending the EUVE seems to be virtually assured, however, as NASA plans to use it as an experiment in reducing operational costs by turning the satellite over to a university to run. The University of California at Berkeley, which already operates EUVE's science instruments from its Center for Extreme Ultraviolet Astrophysics (CEA), would take over full responsibility for the satellite from NASA's Goddard Space Flight Center in Greenbelt, Maryland, perhaps as early as next winter.

Roger Malina, the director of CEA, says that, by relying heavily on artificial intelligence and other automated techniques, and by using students rather than government workers and contractors, Berkeley should be able to run the satellite "a lot cheaper" than NASA - as little as $\$ 3.5$ million a year.

Riegler is more cautious, saying that the plan to hand over EUVE is an "experiment" that will initially cost his office more money, at least in the transition phase when Goddard and Berkeley will share control of the spacecraft. But NASA's hope - and its policy with future scientific spacecraft - is to save money by "outsourcing" and automating mission operations as much as possible.

In the case of the larger and more complex GRO, outsourcing mission operations to a single university is unlikely. So the project has tried to save costs in other ways - for example, by switching from a multimission control room at Goddard to control through distributed workstations.

Such streamlining may eventually be able to cut operations costs in half, down to an estimated $\$ 8$ million a year by the end of the decade. But that alone would break NASA's allotted budget for fiscal year 2000 for operating the missions under consideration at this month's review.

And GRO, too, is likely to survive on scientific merit. It covers a wavelength range that no other satellite does, it addresses a high-priority scientific problem - the nature of gamma-ray bursts - and no other spacecraft is being built to replace it. "We don't have anyone nipping at our heels," says Gerald Fishman of NASA's Marshall Space Flight Center in Huntsville, Alabama, principal investigator for one of GRO's instruments.

Tony Reichhardt

\section{Internet data warning}

Paris. French research organizations and universities that include details of researchers in directories published on the Internet should first ask individual researchers for their formal authorization, according to CNIL, the body that supervises the enforcement of the French data-protection act. In its annual report, released last week, CNIL also warned that computer systems should be designed to prevent confidential medical data on individuals from falling into the wrong hands. (See also page 198.) $\square$ 